\title{
PENGARUH KEPUASAN KERJA, KOMPENSASI DAN PENGEMBANGAN KARIR TERHADAP TURNOVER INTENTION KARYAWAN BANK SYARIAH MANDIRI CABANG PADANG
}

\author{
Vicky Brama Kumbara \\ Universitas Putra Indonesia YPTK Padang \\ Email : vicky.brama@ yahoo.co.id
}

\begin{abstract}
Abstrak
Penelitian ini bertujuan untuk menentukan pengaruh kepuasan kerja, kompensasi dan pengembangan karir terhadap turnover intention karyawan BSM cabang Padang. Populasi dalam penelitian ini adalah karyawan tetap BSM cabang Padang. Jumlah sampel penelitian ditentukan berdasarkan rumus Slovin sebanyak 84 orang dan dipilih dengan menggunakan teknik cluster random sampling. Data yang digunakan yaitu data primer dan data sekunder. Teknik analisis data dengan menggunakan analisis jalur dan uji hipotesis dengan uji t dengan analisis data menggunakan bantuan program SPSS versi 20. Hasil penelitian berdasarkan analisis jalur menunjukkan bahwa kompensasi dan pengembangan karir berpengaruh positif dan signifikan terhadap kepuasan kerja. Sementara itu, kompensasi, pengembangan karir dan kepuasan kerja secara bersama-sama berpengaruh signifikan terhadap turnover intention. Akan tetapi secara individual hanya kepuasan kerja yang berpengaruh signifikan dan bernilai negatif terhadap turnover intention.
\end{abstract}

Kata kunci : Kepuasan kerja, Kompensasi, Pengembangan karir, Turnover intention

\section{PENDAHULUAN}

Turnover intention merupakan kadar dari keinginan untuk keluar dari perusahaan yang didasari oleh berbagai alasan seperti untuk mendapatkan pekerjaan yang lebih baik. Biasanya keputusan untuk berpindah kerja merupakan salah satu pilihan terakhir bagi seorang karyawan apabila dia mendapati kondisi kerjanya sudah tidak sesuai dengan apa yang diharapkannya. Adanya turnover intention ini bisa diindikasikan melalui beberapa perilaku seperti mencari-cari informasi tentang pekerjaan lain, absensi yang meningkat, mulai malas bekerja, pelanggaran terhadap peraturan, peningkatan protes terhadap atasan, atau bahkan perilaku positif yang berbeda dari biasanya.

Indikasi-indikasi turnover intention di atas bisa ditemukan di banyak perusahaan tidak terkecuali di Bank Syariah Mandiri (BSM) cabang Padang. Untuk mengamati fenomena turnover intention di BSM cabang Padang maka penulis telah melakukan pengamatan awal dan wawancara berkaitan dengan data jumlah karyawan BSM cabang Padang yang telah berhenti bekerja sejak tahun 2011 hingga 2014 sebagaimana ditampilkan pada Tabel 1.

Tabel 1

Jumlah Karyawan BSM Cabang Padang yang berhenti

\begin{tabular}{|c|c|c|c|c|}
\hline \multicolumn{5}{|c|}{ Jumlah Karyawan BSM Cabang Padang yang berhenti } \\
\hline & \multicolumn{2}{|c|}{ Alasan berhenti } & \multirow[b]{2}{*}{ Jumlah } & \multirow{2}{*}{$\begin{array}{l}\text { rata-rata } \\
\text { per tahun }\end{array}$} \\
\hline karyawan & $\begin{array}{c}\text { mengundurkan } \\
\text { diri }\end{array}$ & di pecat & & \\
\hline Tetap & 24 & 4 & 28 & 7,00 \\
\hline Tidak tetap & 40 & 19 & 59 & 14,75 \\
\hline Jumlah & 64 & 23 & 87 & 21,75 \\
\hline
\end{tabular}

Berdasarkan Tabel 1 dapat diketahui bahwa rata-rata karyawan BSM cabang Padang yang berhenti setiap tahunnya selama periode tahun 2011 hingga 2014 adalah sebanyak 7 orang untuk karyawan tetap dan 15 orang untuk karyawan tidak tetap. Secara umum BSM cabang Padang kehilangan 22 orang karyawan setiap tahun dan angka tersebut cukup mengkhawatirkan.

Pada dasarnya, intention turnover bisa muncul karena ada banyak faktor yang berperan. Faktor-faktor tersebut diantaranya tingkat kepuasan kerja, bagaimana kompensasi yang diterapkan oleh perusahaan, dan pengembangan karir.

Kepuasan kerja merupakan salah satu hal yang penting dimiliki oleh setiap orang dalam bekerja. Dalam berbagai literatur dan dari hasil penelitian, kepuasan kerja merupakan salah satu faktor penting yang 
berhubungan dengan alasan terjadinya turnover. Biasanya jika karyawan merasa tidak puas terhadap pekerjaannya maka ia dapat menunjukkan ketidakpuasan tersebut dengan berbagai cara salah satunya adalah keluar (exit) sebagai tindakan meninggalkan pekerjaan termasuk mencari pekerjaan lain.

Baik turnover intention maupun kepuasan kerja memiliki hubungan yang erat dengan sistem kompensasi dalam suatu perusahaan, baik itu gaji, insentif, tunjangan dan fasilitas. Karyawan yang mendapatkan kompensasi yang sesuai dengan harapannya biasanya akan memiliki kepuasan yang kerja yang tinggi, selanjutnya dapat meminimalisasi turnover intention.

Jika dihubungkan kembali dengan fenomena turnover intention karyawan BSM cabang Padang, mungkin hal ini bisa berhubungan dengan kompensasi, namun bisa jadi tidak. Bisa jadi berhubungan dengan kompensasi karena memang sistem kompensasi di BSM berbeda dengan bank lainnya. Misalnya, perhitungan uang cuti, bonus dan insentif di BSM semuanya dihitung dengan dasar perkalian terhadap upah pokok dan tunjangan grade saja, bukan berdasarkan Take Home Pay (THP) atau sistem single salary. Sementara Bank lain menerapkan sistem pembayaran berdasarkan perkalian terhadap THP sehingga nominal yang diterima karyawan jauh lebih besar. Namun, bisa jadi fenomena turnover intention ini tidak berhubungan dengan kompensasi karena ada label yang diberikan sebagian orang bahwa orang-orang yang bekerja di bank syariah adalah orang-orang yang berjihad dimana bekerja dinilai sebagai sebuah ibadah sehingga masalah kompensasi tidak begitu menjadi persoalan, yang paling utama adalah ibadah itu sendiri.

Selain kompensasi, adanya pengembangan karir yang menjanjikan juga merupakan faktor yang dapat meningkatkan kepuasan kerja karyawan sekaligus menurunkan turnover intention. Menurut Siagian (2007:215) semakin baik kesempatan karyawan untuk mengembangkan karirnya maka semakin besar kepuasan kerja karyawan sehingga dapat berdampak pada hasil kerja yang lebih baik.

Sebelum tahun 2013, pengembangan karir di BSM memang tergolong cukup cepat hal ini salah satunya dipicu dengan banyaknya pembukaan outlet baru setiap tahun sehingga promosi karyawan untuk jabatan yang lebih tinggi terjadi dengan cepat. Akan tetapi, memasuki tahun 2014 pembukaan outlet baru sangat terbatas dan melalui proses yang cukup panjang, bahkan di 2015 ini ada beberapa outlet yang statusnya mengalami downgrade menjadi Kantor Cabang Pembantu (KCP) atau Kantor Kas (KK). Tentu saja hal ini berpengaruh terhadap pengembangan karir. Oleh karena posisi jabatan untuk masing-masing outlet telah penuh akhirnya menyebabkan promosi karyawan menjadi lebih lambat. Pada awalnya tentu ketika karyawan berlomba-lomba untuk bergabung dengan BSM salah satunya karena mendapatkan informasi tentang pengembangan karir yang cukup baik dan cepat, tetapi setelah bergabung ternyata terjadi perubahan. Namun, apakah hal ini juga menjadi faktor yang mempengaruhi fenomena-fenomena turnover intention, masih belum diketahui sehingga layak untuk diteliti.

Adapun tujuan dari penelitian ini yaitu :

a. Menentukan pengaruh kompensasi terhadap kepuasan kerja karyawan BSM cabang Padang.

b. Menentukan pengaruh pengembangan karir terhadap kepuasan kerja karyawan BSM cabang Padang.

c. Menentukan pengaruh kompensasi terhadap turnover intention karyawan BSM cabang Padang.

d. Menentukan pengaruh pengembangan karir terhadap turnover intention karyawan BSM cabang Padang.

e. Menentukan pengaruh kepuasan kerja terhadap turnover intention karyawan BSM cabang Padang.

\section{KAJIAN TEORI}

Mathis dan Jackson (2001:102) secara sederhana menyatakan bahwa turnover intention adalah proses dimana tenaga kerja berkeinginan meninggalkan organisasi dan harus ada yang menggantikannya. Menurut Zeffane (dalam Hanafiah, 2014:306) turnover intention adalah kecenderungan atau niat karyawan untuk berhenti bekerja dari pekerjaanya secara sukarela menurut pilihannya sendiri. 
Copyright@2018 by LPPM UPI YPTK Padang

Yulianto (dalam Sidharta dan Margaretha, 2011:130) mengemukakan bahwa turnover intention merupakan salah satu bentuk perilaku menarik diri (withdrawal) dalam dunia kerja, akan tetapi sekaligus juga merupakan hak bagi setiap individu untuk menentukan pilihannya, apakah tetap bekerja atau keluar dari perusahaan tersebut. Mobley (2000) menambahkan bahwa turnover intention adalah penghentian keanggotaan dalam organisasi oleh individu yang berkeinginan untuk pindah kerja dengan menerima upah moneter dari organisasi. Menurut Tett dan Meyer (dalam Sutanto dan Gunawan, 2013:80), turnover intention merupakan kesadaran dalam diri seseorang untuk meninggalkan suatu organisasi yang ada saat ini, atau dengan arti lain bahwa seseorang berusahan untuk mencari kesempatan kerja yang baru.

Berkaitan dengan kepuasan kerja, Suwatno (2001:187) menyatakan bahwa kepuasan kerja merupakan suatu kondisi psikologis yang menyenangkan atau perasaan karyawan yang sangat subjektif dan sangat tergantung pada individu yang bersangkutan dan lingkungan kerjanya, dan kepuasan kerja merupakan suatu konsep multificated (banyak dimensi), ia dapat memakai sikap secara menyeluruh atau mengacu pada bagian pekerjaan seseorang.

Supatmi, Nimran dan Utami (2012:28) juga mengutip pernyataan Luthans bahwa kepuasan kerja menyangkut beberapa hal pokok antara lain:

1. Kepuasan kerja tidak dapat dilihat, tetapi hanya dapat diduga keberadaannya karena kepuasan kerja menyangkut persoalan emosi atau respon pekerja dari situasi kerja yang dihadapi.

2. Kepuasan kerja menyangkut kesesuaian hasil kerja yang diperoleh dengan harapan para pekerja.

3. Kepuasan kerja sangat terkait dengan persoalan: pekerjaan itu sendiri, kesempatan promosi, gaji, supervisi maupun rekan kerja.

Dari beberapa definisi di atas dapat disimpulkan bahwa kepuasan kerja merupakan rasa menyenangkan atau tidak menyenangkan yang dirasakan oleh karyawan, secara langsung berpengaruh pada emosional dan tingkah laku dalam bekerja berupa kinerja karyawan.

Ada lima faktor yang dapat mempengaruhi kepuasan kerja menurut Kreitner dan Kinicki (2001) dalam Wibowo (2007: 302). Faktor-faktor tersebut diantaranya : (1) pekerjaan itu sendiri (work it self), (2) hubungan dengan atasan (supervision), (3) teman sekerja (workers), (4) promosi (promotion), dan (5) gaji atau upah (pay).

Selanjutnya berhubungan dengan kompensasi sebagai salah satu faktor yang dapat mempengaruhi turnover intention, terdapat begitu banyak pengertian kompensasi yang dikemukakan oleh para penulis. Dessler (1998:85) menyatakan bahwa kompensasi karyawan merujuk pada semua bentuk upah atau imbalan yang berlaku dan muncul dari pekerjaan mereka. Sementara itu, Martoyo (2000:78) menjelaskan bahwa kompensasi merupakan balas jasa yang diberikan oleh organisasi kepada karyawan yang dapat bersifat finansial maupun non finansial, pada periode yang tetap. Sistem kompensasi yang baik akan mampu memberikan kepuasan bagi karyawan dan memungkinkan organisasi memperoleh, mempekerjakan dan mempertahankan karyawan.

Marwansyah (2014:269) mengemukakan beberapa pengertian mengenai kompensasi yakni sebagai:

1. Keseluruhan imbalan yang diberikan kepada karyawan sebagai balasan jasa atau kontribusi mereka terhadap perusahaan.

2. Sesuatu yang diterima oleh seorang karyawan sebagai balasan atas kontribusinya kepada organisasi.

3. Pembayaran kepada seorang karyawan sebagai balasan atas kontribusinya kepada organisasi Pembayaran yang diberikan oleh organisasi/perusahaan kepada seorang karyawan sebagai balasan atas jasa yang diberikannya kepada organisasi/perusaaan.

4. Penghargaan atau imbalan, baik langsung maupun tidak langsung, finansial maupun non finansial, yang adil dan layak kepada karyawan sebagai balasan atas kontribusi/jasanya terhadap pencapaian tujuan organisasi.

Faktor lainnya yang dapat mempengaruhi turnover intention adalah pengembangan karir. Menurut Marwansyah (2014:223), pengembangan karir merupakan kegiatan-kegiatan pengembangan diri yang ditempuh oleh seseorang untuk mewujudkan rencana karir pribadinya. Menurut Wahyudi (2002), dalam pengembangan karir perlu dipahami dua proses, yaitu bagaimana seseorang merencanakan dan mengimplementasikan tujuan karirnya sendiri (career planing) dan bagaimana institusi merancang dan mengimplementasikan program pengembangan karirnya (career management). 
Pengembangan karir dapat dilihat dari dua perspektif ini yaitu individu dan institusi. Perencanaan karir seseorang yang berpusat pada individu adalah perencanaan yang lebih berpusat pada karir individu, sedangkan yang berpusat pada institusi adalah yang fokus pada pekerjaan dan pengidentifikasian jalan karir yang memberikan kemajuan yang logis atas orang-orang di antara pekerjaan dalam organisasi.

\section{METODE PENELITIAN}

Penelitian ini dilaksanakan BSM cabang Padang dengan wilayah kerja tersebar di beberapa kabupaten/kota di Sumatera Barat. Objek yang diteliti adalah karyawan tetap BSM cabang Padang. Populasi dalam penelitian ini adalah karyawan tetap BSM cabang Padang yang berjumlah 106 orang, yang tersebar di 9 outlet yaitu 1 Kantor Cabang (KC) dan 8 kantor cabang Pembantu (KCP).

Sampel penelitian dipilih berdasarkan teknik cluster random sampling. Jumlah sampel penelitian ditentukan dengan menggunakan rumus Slovin (Sugiyono, 1999:273) dengan tingkat kesalahan pengambilan keputusan dianggap 5\% sehingga jumlah sampel dalam penelitan ini adalah 84 orang.

Data hasil penelitian dianalisis dengan menggunakan analisis jalur (Path analsys) dengan bantuan program SPSS versi 20.0 dengan diagram sebagaimana terdapat pada Gambar 2.

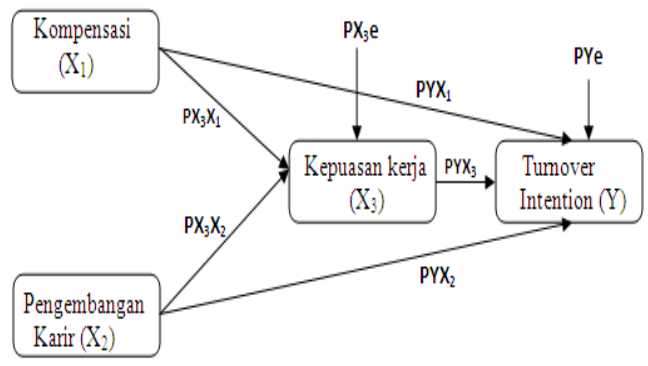

Gambar 2. Diagram Jalur Penelitian

\section{HASIL PENELITIAN}

Tabel 2 berikut ini menyajikan hasil analisis jalur pengaruh variabel kompensasi $\left(\mathrm{X}_{1}\right)$ dan pengembangan karir $\left(\mathrm{X}_{2}\right)$ terhadap kepuasan kerja $\left(\mathrm{X}_{3}\right)$ karyawan BSM cabang Padang.

Tabel 2.

Koefisien Jalur Kompensasi dan Pengembangan Karir

Terhadap Kepuasan Kerja

\begin{tabular}{llccc}
\hline No & \multicolumn{1}{c}{ Variabel } & $\begin{array}{c}\text { Koefisien } \\
\text { Jalur }\end{array}$ & thitung & sig \\
\hline 1. & Kompensasi $(\mathrm{X} 1)$ & 0.200 & 2.038 & 0.045 \\
2. & Pengembangan karir $(\mathrm{X} 2)$ & 0.476 & 4.864 & 0.000 \\
\hline & F Hitung $=20.909$ & & & $0,000^{\circ}$ \\
& $\mathrm{R}^{2}=0.340$ & & & \\
\hline
\end{tabular}

Sumber : data primer (diolah) 
Berdasarkan Tabel 2 dapat kita ketahui bahwa kompensasi dan pengembangan karir memiliki pengaruh yang signifikan terhadap kepuasan kerja karyawan BSM cabang Padang dan dapat dilanjutkan dengan analisa sub struktur 2. Koefisien determinasi yang diperoleh dalam perhitungan ini yaitu sebesar 0,340. Dengan demikian pengaruh variabel lain terhadap kepuasan kerja selain variabel kompensasi dan pengembangan karir, dapat dihitung sebagai berikut :

$$
\begin{aligned}
& \mathrm{Px}_{3} \varepsilon=\sqrt{1-\mathrm{R}^{2} \mathrm{x}_{1} \mathrm{x}_{2}} \\
& \mathrm{Px}_{3} \varepsilon=\sqrt{1-0,340} \\
& \mathrm{Px}_{3} \varepsilon=0,812
\end{aligned}
$$

Berdasarkan perhitungan di atas maka dapat kita ketahui bahwa besarnya kontribusi variabel lain tehadap kepuasan kerja karyawan BSM cabang Padang diluar variabel kompensasi dan pengembangan karir adalah sebesar $66,0 \%$

Hasil analisis jalur pengaruh variabel kompensasi $\left(\mathrm{X}_{1}\right)$, pengembangan karir $\left(\mathrm{X}_{2}\right)$ dan kepuasan kerja $\left(\mathrm{X}_{3}\right)$ terhadap turnover intention $(\mathrm{Y})$ disajikan dalam Tabel 3.

Tabel 3.

Koefisien Jalur Kompensasi, Pengembangan Karir dan Kepuasan Kerja Terhadap Turnover Intention

\begin{tabular}{llccc}
\hline No & \multicolumn{1}{c}{ Variabel } & Koefisien Jalur & thitung & sig \\
\hline 1. & Kompensasi (X1) & -0.041 & -0.364 & 0.717 \\
2. & Pengembangan karir (X2) & -0.090 & -0.729 & 0.468 \\
3. & Kepuasankerja (X3) & -0.369 & -2.990 & 0.004 \\
\hline \multicolumn{2}{c}{ F Hitung $=6,542$} & & & $0,001^{\mathrm{b}}$
\end{tabular}

$\frac{\mathrm{R}^{2}=0,197}{\text { Sumber : data primer (diolah) }}$

Berdasarkan Tabel 3 maka dapat kita ketahui bahwa hanya variabel kepuasan kerja yang memberikan pengaruh yang signifikan terhadap turnover intention. Sementara itu, pengaruh variabel kompensasi dan pengembangan karir adalah tidak signifikan. Oleh sebab itu, dilakukan triming untuk mengolah data yang signifikan sehingga diperoleh hasil sebagai berikut (Tabel 4).

Tabel 4.

Koefisien Jalur Kepuasan Kerja Terhadap Turnover Intention

\begin{tabular}{ccccc}
\hline No & Variabel & $\begin{array}{c}\text { Koefisien } \\
\text { Jalur }\end{array}$ & thitung & sig \\
\hline 1. & Kepuasan kerja $\left(\mathrm{X}_{3}\right)$ & $-0,434$ & $-2,990$ & 0,000 \\
\hline & F Hitung $=19,069$ & & & $0,000^{\mathrm{b}}$
\end{tabular}

$$
\mathrm{R}^{2}=0,189
$$

Sumber : data primer (diolah)

Tabel 4 memperlihatkan bahwa kepuasan kerja berpengaruh signifikan terhadap turnover intention. Adapun nilai koefisien determinasi yang diperoleh dalam perhitungan ini sebesar 0,189 dan selanjutnya pengaruh variabel lain yang tidak diteliti dalam penelitian ini dapat ditentukan sebagai berikut :

$$
\begin{aligned}
\mathrm{PY}_{\varepsilon} & =\sqrt{1-\mathrm{R}^{2} \mathrm{YX}_{3}} \\
\mathrm{PY}_{\varepsilon} & =\sqrt{1-0,189} \\
\mathrm{PY}_{\varepsilon} & =\sqrt{0,8110} \\
\mathrm{PY}_{\varepsilon} & =0,9005
\end{aligned}
$$


Adapun pengaruh variabel kepuasan kerja terhadap turnover intention ini dapat ditentukan sebagai berikut :

Pengaruh langsung $\mathrm{X}_{3}$ ke $\mathrm{Y}$ :

$$
\begin{aligned}
\mathrm{Y} \leftarrow \mathrm{X}_{3} \rightarrow \mathrm{Y} & =\left(P_{\mathrm{YX} 3}\right)\left(P_{\mathrm{YX} 3}\right) \\
& =(-0,434)(-0,434) \\
& =0,1884
\end{aligned}
$$

Artinya, pengaruh langsung variabel kepuasan kerja terhadap turnover intention karyawan BSM cabang Padang adalah sebesar 18,84\%. Persentase pengaruh langsung $\mathrm{X}_{3}$ terhadap Y disajikan pada Tabel 4 berikut ini.

Tabel 4.

\begin{tabular}{|c|c|c|c|}
\hline No & Keterangan & $\%$ & $\%$ \\
\hline \multirow[t]{2}{*}{1.} & Pengaruh $\mathrm{X}_{3}$ terhadap $\mathrm{Y}$ secara langsung & 18,84 & \\
\hline & Total pengaruh $\mathrm{X}_{3}$ terhadap $\mathrm{Y}$ & & 18,84 \\
\hline \multirow[t]{2}{*}{2.} & Pengaruh Variabel lain & & 81,16 \\
\hline & Total & & 100,00 \\
\hline
\end{tabular}

Pengaruh Kepuasan Kerja Terhadap Turnover Intention Karyawan BSM Cabang Padang

Sumber : data primer (diolah)

Secara umum setelah dilakukan analisis jalur maka dapat digambarkan struktur jalur dalam penelitian ini yaitu sebagai berikut :

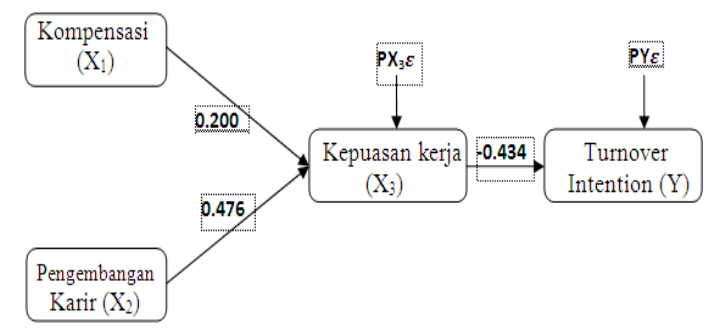

Gambar 4. Struktur akhir analisis jalur penelitian

\section{KESIMPULAN DAN SARAN}

a. Kesimpulan

Berdasarkan hasil penelitian dan pembahasan yang telah dikemukakan maka dapat ditarik beberapa kesimpulan sebagai berikut :

1. Kompensasi memberikan pengaruh yang signifikan an bersifat positif terhadap kepuasan kerja karyawan BSM cabang padang dengan koefisien jalur sebesar 0,200. Hal ini menunjukkan bahwa semakin tinggi kompensasi yang diberikan maka semakin baik pula kepuasan kerja karyawan BSM cabang Padang.

2. Pengembangan karir juga memberikan pengaruh yang signifikan terhadap kepuasan kerja karyawan BSM cabang Padang. Koefisien jalur pengaruh pengembangan karir terhadap kepuasan kerja bernilai positif dan lebih besar jika dibandingkan koefisien jalur pengaruh kompensasi, yaitu 0,476 .

3. Kompensasi, pengembangan karir dan kepuasan kerja ditemukan secara bersama-sama berpengaruh signifikan terhadap turnover intention. Akan tetapi secara individual, baik kompensasi maupun pengembangan karir tidak memberikan pengaruh yang signifikan terhadap turnover intention. Dengan demikian adanya turnover intention karyawan BSM cabang Padang dalam hal ini tidak dipengaruhi oleh besar kecilnya kompensasi ataupun bagiamana pengembangan karir di perusahaan. 
4. Pengaruh kepuasan kerja intention turnover karyawan BSM cabang Padang adalah bersifat langsung dan bernilai negatif. Artinya, semakin puas karyawan BSM cabang Padang terhadap pekerjaannya maka turnover intention akan semakin berkurang karena karyawan yang puas akan bertahan dengan pekerjaannya dan tidak memiliki pikiran-pikiran untuk keluar dari perusahaan, berpindah atau mencari alternatif pekerjaan lainnya.

\section{b. Saran}

Berdasarkan hasil penelitian ini maka maka penulis memberikan beberapa saran sebagai berikut :

1. Sebagai upaya untuk menurunkan atau mencegah terjadinya turnover intention karyawan BSM cabang Padang dapat dilakukan dengan cara meningkatkan kepuasan kerja karyawan, yaitu dengan meningkatkan kompensasi dan pengembangan karir yang baik. Namun perusahaan perlu mempertimbangkan alternatif mana yang memberikan kontribusi paling besar untuk meningkatkan kepuasan kerja karyawan.

2. Upaya meningkatkan kepuasan kerja melalui kompensasi dapat dilakukan terutama dengan meningkatkan insentif atau bonus tahunan bagi karyawan sesuai dengan kontribusinya, meningkatkan gaji/upah yang sesuai, termasuk meningkatkan tunjangan jabatan sesuai dengan beban kerja dan tanggung jawab pekerjaan.

3. Pengembangan karir yang baik untuk menciptakan kepuasan kerja karyawan BSM cabang padang dapat dilakukan dengan beberapa cara seperti memperhatikan kesesuaian antara minat dengan pekerjaan, adanya kejelasan rencana karir jangka pendek dan jangka panjang yang dimilik karyawan, publikasi lowongan internal secara terbuka, promosi karyawan dilakukan secara objektif serta memberikan kesempatan yang sama kepada karyawan dalam hal pendidikan dan pelatihan untuk mempersiapkan karyawan mengembangkan karir baru.

4. Oleh karena tidak terdapat pengaruh langsung dari variabel kompensasi dan pengembangan karir terhadap turnover intention karyawan BSM cabang Padang maka untuk mempelajari turnover intention karyawan BSM Cabang Padang mungkin bisa menggunakan pendekatan variabel lain seperti komitmen organisasi dan karkteristik karyawan seperti usia dan masa kerjanya.

\section{DAFTAR PUSTAKA}

Aksu, A.Akin dan Ayllin Aktas, 2005. Job Satisfaction Of Managers In Tourism Case In The Antalya Region Of Turkey. Managerial Auditing Journal, Vol.20, No.5 pp. 479 - 488

Dawwas, Mohammed I.F. dan Ibrahim Zahare. 2014. Testing the Relationship between Turnover Intention and Human Resource Practices in a non-Western context of the Palestine. Journal of Advanced Social Research Vol.4 No.6, June 2014, 10-22.

Dessler, Gary. 1998. Manajemen Sumber Daya Manusia. Edisi Bahasa Indonesia Jilid 2. Jakarta: PT. Prenhallindo

Hanafiah, Mohammad. 2014. Pengaruh Kepuasan Kerja dan Ketidakamanan Kerja (Job Insecurity) dengan Intensi Pindah Kerja (Turnover) pada Karyawan PT. Buma Desa Suaran Kecamatan Sambaliung Kabupaten Berau. eJournal Psikologi, 2014, 1 (3): 303-312.

Lum, L., Kervin, J., Clark,K., Reid,F dan Sirola,W. 1998. Explaining nursing turnover intent: job satisfaction, pay satisfaction or organizational commitment? Journal of Organization Behaviour. Vol. 19(3) : 305-320.

Mahdi, Ahmad Faisal., Ahmad Faisal Mahdi, Mohamad Zaid Mohd Zin, Mohd Roslan Mohd Nor, Ahamad Asmadi Sakat dan Abang Sulaiman Abang Naim. 2012. The Relationship Between Job Satisfaction and Turnover Intention. American Journal of Applied Sciences 9 (9): 1518-1526, 2012.

Mariana, Sondang Lestari dan Irvianti, Laksmi Sito. 2012. Pengaruh kompensasi dan pengembangan karir Terhadap Turnover Intention Pada PT. APL Indonesia. Di akses dari www.thesis.binus.ac.id/doc/RingkasanInd/2012-1-0025-MN\%20Ringkasan001.pdf pada tanggal 22 Februari 2015.

Martoyo, Susilo. 2000. Manajemen Sumber Daya Manusia Edisi Keempat. Yogyakarta: BPFE. 
Marwansyah. 2014. Manajemen Sumber Daya Manusia. Edisi Kedua. Bandung: Alfabeta.

Mathis, Robert. L dan Jackson, John. H. 1998. Manajemen Sumber Daya Manusia. Jakarta: Penerbit Salemba Empat.

Mobley, W.H. 2000. Pergantian Karyawan: Sebab, Akibat dan Pengendaliannya. Terjemahan. Jakarta: PT Pustaka Binaman Press indo.

Mudor, Hamdia dan Phadett Tooksoon. 2011. Conceptual framework on the relationship between human resource management practices, job satisfaction, and turnover. Journal of Economics and Behavioral Studies Vol. 2, No. 2, pp.41-49, Feb 2011.

Muliana, Siti. 2013. Faktor-Faktor yang Mempengaruhi Keinginan Pindah Kerja Perawat Rumah Sakit Atma Jaya. Tesis Program Magister Manajemen Universitas Esa Unggul Jakarta

Nugroho, Agus Dwi dan Kunartinah. 2012. Analisis Pengaruh Kompensasi dan Pengembangan Karis Terhadap Kepuasan Kerja dengan Mediasi Motivasi Kerja. Jurnal Bisnis dan Ekonomi (JBE), September 2012, Hal. 153-169

Ologunde, Adedoyin Olusola., Asaolu, T.O., dan Elumilade, David Oladapo. 2003. Labor Turnover among University Teachers in Southwestern Nigeria-Issue, Solution and Lesson. Di akses dari http://unpan1.un.org/intradoc/groups/public/documents/AAPAM/UNPAN029860.pdf pada tanggal 22 Februari 2015.

Purbowo, S.A. 2006. Analisis Aspek-Aspek Kepuasan Kerja yang Berhubungan dengan dengan Intention To Quit pada Perawat di RS Mohammad Husni Thamrin International Salemba. Tesis FKM Universitas Indonesia Jakarta.

Robbins, Stephen P. 2003. Perilaku Organisasi. Jakarta: PT. Indeks Kelompok Gramedia.

Siagian, Sondang P. 2007. Manajemen Sumber Daya Manusia. Jakarta: Bumi Aksara.

Sidharta, Novita dan Meily Margaretha. 2011. Dampak Komitmen Organisasi dan Kepuasan Kerja Terhadap Turnover Intention: Studi Empiris Pada Karyawan Bagian Operator di Salah Satu Perusahaan Garment di Cimahi. Jurnal Manajemen,Vol.10, No.2, Mei 2011; Universitas Kristen Maranatha, hal 129-142.

Sopiah. 2008. Perilaku Organisasional : Edisi I. Yogyakarta: CV. Andi Offset.

Sutanto, Eddy M. dan Gunawan, Carin. 2013. Kepuasan Kerja, Komitmen Organisasional dan Turnover Intentions. Jurnal Mitra Ekonomi dan Manajemen Bisnis, Vol. 4, No. 1, April 2013, 76-88

Suwatno dan Donni Juni Priansa. 2011. Manajemen Sumber Daya Manusia, Dalam Organisasi Publik dan Bisnis. Bandung: Alfabeta

Supatmi, Mamik Eko., Umar Nimran dan Hamidah Nayati Utami. 2012. Pengaruh Pelatihan, Kompensasi Terhadap Kepuasan Kerja Karyawan dan Kinerja Karyawan. Jurnal Provit Volume 7 No. I Hal. 25 37.

Wahyudi, Bambang. 2002. Manajemen SumberDaya Manusia. Bandung: Sulita.

Wibowo. 2007. Manajemen Kinerja. Jakarta: PT. Raja Grafindo Persada. 